\title{
CONFERÊNCIA
}

\section{O PROCESSO DE MERCANTILIZAÇÃO DA EDUCAÇÃO E O NOVO CICLO DE REFORMAS EDUCACIONAIS NO BRASIL PÓS-GOLPE \\ INSTITUCIONAL DE 2016}

\author{
Evaldo Piolli
}

\section{INTRODUÇÃO}

Este texto foi elaborado com base na palestra ministrada no dia 16 de março de 2018, intitulada, "O novo ciclo de reformas educacionais no Brasil: gerencialismo e mercantilização". O evento foi promovido pelo Grupo de Estudos e Pesquisas HISTEDBR (História, Sociedade e Educação no Brasil) da Universidade Federal do Oeste do Pará/UFOPA, voltados para os estudantes de graduação, pós-graduação e professores das redes públicas de ensino da região, com quem tivemos a oportunidade de estabelecer um diálogo agradável e proveitoso sobre a conjuntura política e os possíveis efeitos do das recentes reformas educacionais ditados por forças do mercado e implementadas pelo governo atual.

O processo do golpe institucional de 2016 produziu 0 desencadeamento de grandes perdas para a classe trabalhadora, fundamentalmente, os relacionados aos direitos e o desmonte dos serviços públicos e a desmoralização de seus servidores. Entra em vigor o programa "Ponte para o Futuro" que foi apresentado em 2015 pelo então vicepresidente Temer ao empresariado. Na verdade, essa "Ponte" soa mais

\footnotetext{
${ }^{1}$ É professor efetivo do Departamento de Políticas, Administração e Sistemas Educacionais (DEPASE) da Faculdade de Educação da UNICAMP, Campinas/SP. Possui graduação em Ciências Sociais pela Pontifícia Universidade Católica de São Paulo (1989), mestrado e doutorado em Educação pela Universidade Estadual de Campinas. É professor do programa de Pós-graduação em Educação da UNICAMP e líder do Grupo de Pesquisa Trabalho, Saúde e Subjetividade - NETSS. Desenvolve estudos e pesquisas sobre gestão educacional; política educacional; trabalho docente; trabalho, saúde e identidade; trabalho e educação. E-mail: epiolli@yahoo.com.br
} 
como um grande túnel para um passado que tem como objetivo desconstruir os avanços na constituição de 1988 e o acesso aos direitos universais (educação, saúde e previdência social), adotando o argumento falacioso de que esses diretos fixados na constituição "não cabem no orçamento publico". Essas propostas partiram de um diagnóstico de que a política de ajuste fiscal adotada no governo Dilma se mostrava insuficiente.

O documento fazia uma defesa aberta e clara de um projeto de privatização dos serviços públicos, em total confluência com o projeto derrotado nas eleições defendido pelo PSDB. O documento vendeu a ideia de que o Brasil estava "em risco" e de que para "voltarmos a crescer" seria preciso tornar o estado mais "eficiênte" e "funcional", colocando como imperativo o retorno ao "orçamento verdadeiro", defendendo o "fim das indexações" (salário mínimo) e das vinculações constitucionais no orçamento. Ou seja, "colocar o orçamento dentro das possibilidades".

"Nossa crise é grave e tem muitas causas. Para superá-la será necessário um amplo esforço legislativo, que remova distorções acumuladas e propicie as bases para um funcionamento virtuoso do Estado. Isto significará enfrentar interesses organizados e fortes, quase sempre bem representados na arena política" (PMDB; FUNDAÇÃO ULYSSES GUIMARÃES, 2015, p.5).

Em março de 2016, portanto, se encerrou o ciclo da Nova República que tinha a constituição de 1988 como um de seus pilares. Entramos num contexto muito parecido com a Ditadura Civil - Militar (1964-1985) com uma tendência ao recrudescimento das liberdades democráticas e o avanço das forças liberais conservadores e do neoliberalismo radical ditado pelas forças do mercado e pelo grande capital, principalmente $o$ financeiro, e do rentismo. Essa agenda dos ajustes envolveu, primeiramente, a votação da EC 95/2016, seguida pela reforma trabalhista e a reforma da previdência, ainda não votada. Essas medidas se somam a outras como a Desonerações Fiscais e a PEC 87/2015 que trata da Desvinculação das Receitas da União (DRU). 
As desonerações fiscais, para favorecer determinados setores econômicos e vieram sendo implementadas de forma mais expressiva desde o primeiro governo Lula. O PAC (Programa de Aceleração do Crescimento) previa uma série de desonerações para setores como o da construção civil, da infraestrutura pesada e da alta tecnologia. O governo implementou inicialmente, para o enfrentamento da crise de 2008 medidas de redução do IPI para automóveis, para evitar o acúmulo de estoques, o que foi estendido para os setores de consumo de bens duráveis a partir de 2009. No entanto, foi no segundo mandato de Dilma Rousseff que essa política ganhou destaque na política econômica dentro do Plano Brasil Maior, anúnciado em 2011, beneficiando vários setores. Como retrata Carvalho (2018), os setores beneficiados foram: máquinas e equipamentos, materiais de construção, caminhões e veículos, concessão de créditos tributários para exportadores e a desoneração da folha de pagamentos, além da desoneração da cesta básica, envolvendo a redução para isso as alíquotas do PIS/CONFINS e do IPI.

\begin{abstract}
"O conjunto dessas políticas gerou uma forte perda de arrecadação pelo governo federal. O custo anual das renúncias tributárias, que era de 140 bilhões de reais em 2010, passou a ser de 250 bilhões em 2014 , também em valores correntes de cada ano. A estimativa é a de que as desonerações concedidas a partir de 2011 somem 458 bilhões em 2018" (CARVALHO, 2018, p.71).
\end{abstract}

Essa folga nas contas das empresas desses pouco favoreceu a geração de empregos, permitindo que os ganhos de produtividade fossem aplicados em papéis da dívida pública. O setor industrial da burguesia deixa de lado seu furor produtivista para aderir ao rentismo (SINGER, 2016), ao mesmo tempo em que, apresenta seu descontentamento com a política de valorização dos salários e com a política fiscal do governo, defendendo a "austeridade fiscal" e o "controle dos gastos públicos". Essa postura, explica a adesão da FIESP ao documento "Uma ponte para o futuro" e às reformas trabalhista e da previdência. Foi muito expressiva foi a participação e adesão da FIESP, com seu "Pato de Tróia" na Avenida Paulista, às manifestações em apoio ao impeachment de 2016. O efeito nocivo das 
desonerações foi apontado pelo Tribunal de Contas da União (TCU). Em 2017 as renúncias fiscais somaram $R \$ 354,7$ bilhões. Para se ter uma ideia, o deficit primário desse ano de 2018, com o teto dos gastos implantado pela EC 95/2016 será de $R \$ 159$ bilhões.

A PEC 87/2015, de autoria da presidenta Dilma Rousseff, aprovada nos primeiros dias do Governo Temer, prorrogou a Desvinculação das Receitas da União (DRU) até 2023 e amplia de 20\% para 30\% o percentual a ser desvinculado. Esses $30 \%$ das receitas podem ir para outras finalidades, inclusive, para pagamento da dívida, com efeitos diretos à saúde, previdência e assistência. Representa a violação de cláusulas pétreas da Constituição, fundamentalmente do artigo $6^{\circ}$, que fixa que "São direitos sociais a educação, a saúde, a alimentação, o trabalho, a moradia, o transporte, o lazer, a segurança, a previdência social, a proteção à maternidade e à infância, a assistência aos desamparados, na forma desta Constituição". Com a extensão dessa medida para estados e municípios esses direitos podem ficar ainda mais ameaçados (RODRIGUES, 2016).

A DRU constitui-se, portanto, como um reforço substancial às medidas de ajuste para cumprimento das metas fiscais e garantia ao pagamento da dívida, que somada à EC 95/2016 trarão efeitos diretos aos investimentos à Educação, tensionando para medidas de privatização, parcerias públicoprivada e terceirização. Isso está em total conformidade com os princípios defendidos no "Ponte para o futuro" que defende medidas desse tipo, combinada com a proposição das desvinculações das verbas constitucionais, no caso, a obrigatoriedade de aplicação de $18 \%$ dos recursos arrecadados de impostos à educação, conforme o artigo 212 da Constituição Federal.

O Fineduca analisou os possíveis efeitos da EC 95/2016 à educação apontando que com essa medida, que congela os gastos por 20 anos, o percentual de $18 \%$ estaria comprometido, assim como, as metas do novo PNE (2014-2024). O estudo foi elaborado pelo Professor José Marcelino Rezende Pinto e aponta que "considerando-se um crescimento da receita real de 3\% ao ano, após 5 anos a vinculação já estaria em 16\%; após 10 
anos, em 13,8\% e após 20 anos, chegaria a 10,3\%, ou seja, uma redução de $43 \%$ no índice" (FINEDUCA, 2016).

A reversão dessa vinculação de recursos, promovido pela a EC 95/2016, pode ser comparada à quebra da proposição de verbas vinculadas para a Educação, que ocorreu em períodos autoritários como do Estado Novo (1937-1945) e da Ditadura Civil-Militar (1964-1985), que retrocederam avanços nesse sentido. Considerando que em todas as constituições até 1934 não previam vinculações obrigatórias para aplicação na Educação.

Quadro I. Percentual dos recursos de impostos aplicados na Educação conforme as Constituições brasileiras (1934-2018)

\begin{tabular}{llll}
$\begin{array}{c}\text { Constituiçōes e as } \\
\text { alteraçōes }\end{array}$ & \multicolumn{1}{c}{ União \% } & Estados \% & Municipios \% \\
1934 & 10 & 20 & 20 \\
1937 & 0 & 0 & 0 \\
1946 & 10 & 20 & 20 \\
Lei 4024/1961 & 12 & 20 & 20 \\
1967 & 0 & 0 & 0 \\
EC 01/1969 & 0 & 0 & 20 \\
EC 24/1983 & 13 & 24 & 25 \\
1988 & 18 & 25 & 25 \\
EC 95 /2016 & $\begin{array}{l}\text { Desvinculação } 20 \\
\text { Progressiva por 20 } \\
\text { anos }\end{array}$ &
\end{tabular}

Fonte: Elaborado pelo autor.

Conforme a EC n० 95 pelos próximos 20 anos, fica fixado um limite anual para as despesas primárias totais do Governo. A medida estabelece que só se poderá gastar por ano, o valor da despesa do ano anterior, ajustado pela inflação do período. Isso consta do inciso II do $\S 1^{\circ}$ do artigo 107 e sua nova redação. Disso concluí-se que a soma das despesas, entre elas a Educação, ficarão congeladas por duas décadas. Pelo que estamos prevendo a EC 95/2016 promove o sepultamento do PNE (2014-2024), que previa a elevação do percentual de investimento para 10\% do PIB até 2024. 
Há que se considerar que essa PEC, constitui-se como uma ameaça concreta ao FUNDEB, reduzindo ainda mais a participação da União junto aos Estados e Municípios no fundo. Poderá agravar ainda mais o quadro crônico que afeta a distribuição dos recursos do Fundo para Pagamento de pessoal, que é de no mínimo $60 \%$ e para os investimentos em MDE que é de $40 \%$, fragilizando a concepção e os princípios do Fundo, afetando cerca de 40 milhões de crianças matriculadas nas escolas públicas.

A EC somada a Lei Complementar n ${ }^{\circ} 101$, ou Lei de Responsabilidade Fiscal (LRF), serão indutoras da intensificação de medidas em favor da transferência de responsabilidades do Estado para o setor privado se intensifiquem. A LRF tem se fixado como um mecanismo impeditivo à contratação de profissionais na área da educação, fomentando, ao longo dos anos, a contratação precária de professores e a terceirização massiva.

A combinação de fatores acima descrita, atrelada ao falcioso discurso da falta de recursos, estão sendo utilizados para justificar a aceleração de reformas educativas, que devem beneficiar ainda mais, já no curto prazo, o setor privado-mercantil. No ensino superior os estímulos são expressivos e envolvem o acesso ao crédito e bolsas, dentro do programa FIES e do PROUNI. Na educação básica, grandes grupos privados de capital aberto se movimentam, focalizando a educação básica para atender os novos requisitos fixados pela BNCC e a Reforma do Ensino Médio. Com essas reformas na educação básica, bancadas pelo setor empresarial, como veremos no próximo tópico, as possibilidades de negócios para os grandes grupos privados se expandem ainda mais, não mais para a oferta de vagas no ensino superior, mas para uma gama mais ampla de serviços que envolvem consultorias, produção de materiais didáticos, plataformas de Ead entre outros. Essas reformas, portanto, abrem espaço para que sejam 
ampliadas as formas de acesso aos fundos públicos e de aprofundamento do processo de mercantilização² da educação.

\section{Mercantilização da Educação em todos os níveis: o que o golpe de 2016 tem a ver com isso?}

O golpe institucional de 2016 deu acento no MEC, poder a uma coligação liberal conservadora, composta por partidos como o DEM e o PSDB que advoga uma agenda política e econônomica neoliberal atrelada aos interesses privados do setor educacional. Os ocupantes do ministério aceleram reformas que estão vinculadas ao projeto educacional dos reformadores empresariais, representados, principalmente, pela organização "Todos pela Educação". Esses atores, se antes orbitavam o MEC, hoje estão dando as cartas, acelerando reformas indutoras que ampliam as possibilidades de acesso aos fundos públicos pelo setor privado-mercantil, o que está em sintonia com os princípios, históricamente defendidos pela Organização Mundial do Comércio (OMC), que compreende a educação como uma mercadoria, um serviço e não um bem público.

As forças do mercado, que hoje se ocupam da agenda educacional brasileira, ganharam força e propulsão a partir de uma série de medidas e de regulações que foram fixadas desde a década de 1990, dentro do projeto de reforma do Estado conforme os critérios da Nova Gestão Pública. Sob tais critérios foi-se implementando um marco regularório que deu condições para a maior flexibilização das parcerias público-privado e da privatização no âmbito das políticas públicas. Portanto, trata-se de um processo que antecede ao ano de 2016 no qual foi se consolidando um projeto disseminado pelos organismos internacionais, cuja hegeminia, se deu a partir do discurso do consenso e do "interesse comum" e da "conciliação de classes" tendo como centro a melhoria da qualidade e da gestão (SOUZA, 2018).

\footnotetext{
2 De acordo com Sguissardi (2008), apoiado em Marx, a mercantilização expressa-se como um fenômeno que revela a tendência inexorável da sociedade capitalista de transformar bens materiais e simbólicos em mercadorias.
}

Revista Exitus, Santarém/PA, Vol. 9, Nº 1, p. 17 - 33, JAN/MAR 2019. 
A concepção de qualidade hegemônica é a que está submetida aos critérios da racionalidade empresarial, tida como a mais eficaz e objetiva e neutra, por estar submetida a critérios de quantificação. No debate educacional o elemento político principal foi a gestão e a mobilização da "sociedade civil" como elementos fundamentais para implantação das reformas no Brasil. A objetividade seria obtida com o devido acompanhando das tendências mundiais que compreendem a qualidade da educação vinculada a melhoria dos indicadores e na posição em rankings, como o Programa Internacional de Avaliação de Estudantes (PISA) 1. Isso combinado com estratégias voltadas para a formação de Capital Humano para a maior produtividade do capital no contexto da acumulação flexível.

No Brasil a expressão disso foi o da criação, em 2005, da organização "Todos pela Educação" 3 surgida por iniciativa de um grupo de lideranças do setor empresarial e que hoje atua em nível nacional. Em 2006, em evento realizado no Museu do Ipiranga em São Paulo, ocorre a formalização dessa organização, com o lançamento do documento "Compromisso Todos pela Educação". O documento é apresentado como uma "iniciativa da sociedade brasileira" com a missão de "garantir a todas as crianças e jovens o direito a Educação Básica de qualidade" até o ano de 2022. Desse modo, o setor empresarial passa a disputar, de forma mais intensa e sistemática, a agenda educacional. Como decorrência disso, o MEC lança, em 24 de abril de 20074, o Plano de Desenvolvimento da Educação - PDE, o qual reforçou e estimulou, em âmbito federal, a aproximação do setor empresarial nas decisões relativas à educação e as tendências gerenciais centradas na responsabilização. Esse plano consistiu de um conjunto de 30 ações, centradas na "melhoria da qualidade".

3 Composição do "Todos pela Educação": Mantenedores: Fundação Educar DPASCHOAL,Fundação Bradesco,Fundação Itaú Social, Fundação Telefônica (Vivo), Gerdau, Instituto UNIBANCO,Itaú BBA,Santander, SUZANO, Fundação Lemann, Instituto Peninsula, Fundação Vale, Instituto Natura, Instituto Samuel Klein. Os parceiros são: Grupo $A B C, D M 9 D D B$, Rede Globo, Editora Moderna, Fundação Santillana, Instituto Ayrton Senna, Friends Audio, Fundação Victor Civita, McKinsey Brazil, Microsoft, Instituto Paulo Montenegro, Banco HSBC, Futura, Editora Saraiva, BID - Banco Interamericano de Desenvolvimento, PATRI - Políticas Pública, Luzio, Itaú Cultural.

${ }_{4}^{4}$ Decreto n. 6.094, Plano de Metas Compromisso Todos pela Educação. 
Saviani (2007) destaca que no contexto indicado o PDE que leva o nome de 'Plano de Metas Compromisso Todos pela Educação', assume plenamente, inclusive na denominação, a agenda do 'Compromisso Todos pela Educação'.

\begin{abstract}
A ementa do Decreto destaca: Dispõe sobre a implementação do Plano de Metas Compromisso Todos pela Educação, pela União Federal, em regime de colaboração com Municípios, Distrito Federal e Estados, e a participação das famílias e da comunidade, mediante programas e ações de assistência técnica e financeira, visando a mobilização social pela melhoria da qualidade da educação básica (SAVIANI, 2007, p. 1243).
\end{abstract}

O PDE vinculou a permanência na escola à qualidade do ensino instituindo O IDEB como principal instrumento para aferi-la. O Ideb é composto pelo resultado dos alunos em avaliações aplicadas em todo país, como a Prova Brasil e o Sistema de Avaliação do Ensino Básico (Saeb) como também, pelas taxas de aprovação e de evasão escolar. Para ter acesso aos programas federais, à assistência técnica e aos recursos adicionais do MEC os Estados e Municípios aderem ao Programa de Ações Articuladas (PAR), que é uma espécie de PDE local, e se comprometem com as metas para melhoria dos resultados. O PDE decreta, portanto, a entrada de dos Reformadores Empresariais (FREITAS, 2012) e sua agenda para a educação no Brasil centrada nas avaliações, na quantificação e no gerencialismo.

O PNE apresentado sob a Lei 13005/2014 reproduz em muitas de suas metas e estratégias, as metas fixadas no PDE. No entanto, dois pontos do referido plano podem ser destacados como expressão dos interesses no mercado e dos reformadores empresariais na educação. O primeiro consta do artigo $5^{\circ}$, parágrafo $4^{\circ}$ da lei que trata da execução do PNE e do cumprimento de suas metas onde fica claro que para o cumprimento das metas não faltarão incentivos governamentais.

$\S 40$ O investimento público em educação a que se referem o inciso VI do art. 214 da Constituição Federal e a meta 20 do Anexo desta Lei engloba os recursos aplicados na forma do art. 212 da Constituição Federal e do art. 60 do Ato das Disposições Constitucionais Transitórias, bem como os recursos aplicados nos 
programas de expansão da educação profissional e superior, inclusive na forma de incentivo e isenção fiscal, as bolsas de estudos concedidas no Brasil e no exterior, os subsídios concedidos em programas de financiamento estudantil e 0 financiamento de creches, pré-escolas e de educação especial na forma do art. 213 da Constituição Federal (BRASIL, 2014).

O setor empresarial, alinhado em torno do movimento "Todos pela Educação", obteve outra grande vitória na promulgação do PNE ao garantir que as práticas meritocráticas e de responsabilização docente, presentes na meta 7.36, constassem do texto final do Plano. Tal lógica foi reforçada na redação do documento "Pátria Educadora", publicado em abril de 2015, pela Secretaria de Assuntos Estratégicos (SAE). O texto reforça a meritocracia de caráter empresarial ao prever a premiação de escolas e a bonificação para professores e diretores, além de abrir a possibilidade de maior exposição dos profissionais que não cumprem metas. De modo geral, podemos dizer que o PNE, com essa medida, promoveu o adiamento do reconhecimento pleno da profissão e sua efetiva valorização nos pilares da formação, carreira, salários e condições de trabalho, jogando para 2024 o pleno reconhecimento (Metas 15, 16, 17 e 18), implantando de imediato, políticas centradas nas avaliações externas, a meritocracia e a responsabilização (PIOLLI, 2015a e 2015b).

$\mathrm{Na}$ educação superior, a expressiva expansão do setor privadomercantil, com um significativo aumento das matrículas nas Instituições de Ensino Superior, foi provocada por fatores condicionantes governamentais como o FIES, fixado pela Lei 10260/2001 e sua reformulação Lei 11552/2007 e o PROUNI, fixado pela Lei 11096/2005, e, também, dos fatores condicionantes de mercado decorrente da flexibilização da legislação em favor do mercado, como o Decreto $n^{\circ} 2.306$, de 10 de agosto de 1997. Na verdade, o quadro permitiu que o mercado se expandisse com grandes operações de fusões e aquisições do setor, criando conglomerados de capital aberto muito lucrativos e que hoje atuam na formulação de políticas para o setor, em todos os níveis, e em defesa de seus interesses e dos lucros para seus investidores. 
O novo ciclo de reformas iniciado em 2016, como a reforma do ensino médio e a BNCC, pode ser considerado como um dos principais fatores na indução do atual movimento de aquisição e fusão movido por grandes grupos privados da educação superior na educação básica. São novas possibilidades de negócios e lucros, não apenas para a oferta de vagas, mas também, para uma gama mais ampla de serviços que envolvem consultorias, produção e venda de materiais didáticos, plataformas de EaD entre outros.

\section{Educação como negócio e fonte de lucro: um assunto para os cadernos de economia da grande imprensa}

Como dissemos, o expressivo aumento das matrículas nas IES do setor privado-mercantil, ocorreram por estimulos governamentais e mudanças no marco regulatório. Esse quadro provocou um salto de 3,6 milhões de matrículas em 2006 para 6 milhões em 2016. Em 2016 o setor privado já concentrava $87,7 \%$ das instituições, contra $12,3 \%$ das públicas (INEP, 2016).

Os valores empregados pelo governo no FIES em 2010 atingiram o montante de 1 Bilhão equivalente a $13 \%$ dos gastos com o Ensino Superior. Em 2014, os valores chegaram a 15,9 bilhões expressando um aumento de 12 vezes o custo registrado em 2014. As IES privadas, ficam entre as empresas que mais receberam recursos do governo federal. Para se ter uma ideia, somente a Kroton-Anhanguera recebeu em 2014 cerca de 2 bilhões. Informações do Portal da Transparência do governo federal dão conta de que em 2010, o governo gastava $R \$ 13$ para cada $R \$ 100$ investidos em Universidades Públicas. Em 2014, os gastos com o programa passaram a ser 19\% maior que os gastos nas instituições públicas (BURGARELLI, 2017).

Todos esses elementos contribuíram para que 0 mercado se expandisse com grandes operações de fusões e aquisições do setor, criando conglomerados de capital aberto muito lucrativos. Esse é o mesmo movimento - de aquisição e fusão - que se anuncia na educação básica a partir do ingresso de grandes grupos econômicos no setor. Entre 2007 e 2016 ocorreram 142 fusões e aquisições que movimentaram 11 bilhões de reais. No 
período houve a chegada de grandes grupos estrangeiros e de empresas de capital aberto.

Quadro 2. Maiores grupos privados de educação no Brasil em matrículas 2016 (mil)

\begin{tabular}{|c|c|}
\hline Grupo & Matrículas \\
\hline Kroton & 877,03 \\
\hline Estácio & 436,3 \\
\hline Unip & 403,36 \\
\hline Laureate & 245,92 \\
\hline Ser Educacional & 137,73 \\
\hline Uninove & 131,73 \\
\hline Cruzeiro do Sul & 102,29 \\
\hline Anima & 85,14 \\
\hline Devry & 75 \\
\hline Uniceumar & 66,96 \\
\hline
\end{tabular}

Fonte: Hoper Educação /infográficos da Folha (2016)

Elaboração: Autor

Essas empresas, atuam não apenas na oferta de vagas, mas também, em escala com a venda de materiais didáticos. Os preços atrativos aplicados decorrem, em grande parte, devido a adoção de esquemas de gerenciamento que enxugam as estruturas, tais como: a padronização curricular, junção de turmas, com redução do quadro de professores, flexibilização dos contratos e a implantação de diferentes modalidades de curso (presencial, semi-presencial e, à distancia). Com o emprego da Ead, inclusive nos cursos presenciais, surge a figura do tutor em substituição ao professor.

Os grandes grupos educacionais já atingem a maior parte das graduações a distância oferecidas no País, conforme o levantamento feito pela FGV. A participação saltou de 15\%, em 2010, para 59,1\% em 2014, um crescimento de $293,3 \%$. A estratégia é adotada principalmente pelos grupos Kroton (crescimento de 701.127,8\%), Estácio $(347,6 \%)$ e Laureate $(576,7 \%)$ (ESTADÃO, 2016). 
Com recursos públicos à disposição, por meio do financiamento estudantil, grupos transnacionais começaram a atuar no Brasil a partir de meados dos anos 2000. Conforme informam Macedo et al (2017), a aquisição de IES brasileiras por grupos internacionais passou a ser uma realidade, com a modificação do marco regulatório da educação superior na década 1990, baseado na Reforma do Aparelho do Estado. No Brasil operam, até o momento, três grandes players transnacionais no ensino superior. São eles: Laureate International Universities, DeVry University e Whitney International University System. Em números isso representa um total de 29 IES com a oferta de 1055 cursos de graduação (MACEDO et al., 2017).

A proposição da BNCC e da Reforma do ensino médio já movimentam o mercado educacional. Ambas as reformas, implantadas após o golpe de 2016, sob a batuta dos Reformadores Empresariais, ampliam possibilidades e diversificam formas de acesso aos fundos públicos da educação por parte do setor privado-mercantil da educação.

No que concerne à BNCC, os reformadores empresariais representados pelo movimento pela base, implantam um gerencialismo autoritário na educação brasileira, centrado em avaliações e responsabilização docente. É o que no campo da gestão empresarial, se convencionou chamar de Benchmarking, que nada mais é, do que um processo de avaliação contínua do trabalhador e do desempenho baseado em resultados quantitativos. A implantação da base nos sistemas de ensino, de cara, abre espaço para um grande mercado ofertar um leque variado de produtos e serviços, tais como, consultorias e a produção e distribuição de materiais didáticos, principalmente via o PNLD, e na formação de professores em serviço, por exemplo. Apostilamento das redes de ensino de interesse de grandes grupos do mercado educacional. Já a Reforma do Ensino Médio, oferece grande potencial para os interesses privados da Educação. Pelo que estamos prevendo, isso ocorrerá muito em função da expansão da carga horária das atuais 800 horas anuais ( 4 horas diárias) para 1 mil (5 horas diárias) em um prazo máximo de 5 anos e pela oferta das terminalidades, principalmente para a Formação Profissional. Com a flexibilização do 
currículo prevista na BNCC (60\% obrigatório e $40 \%$ flexível) e as terminalidades propostas na Reforma do Ensino Médio, a EaD tende a aparecer com força. Para isso basta considerarmos o dado da realidade, pois dentro de um total de 5770 municípios brasileiros, apenas 53\% (2967) oferecem o Ensino Médio regular ou profissionalizante e mais, desse total, 41,9\% das escolas do País trabalham em turno triplo (INEP, 2016).

Os grandes grupos privados da educação, ao longo desse período, acumularam Know-how suficiente no desenvolvimento de produtos em escala, que podem ser disponibilizados para atender essas novas demandas colocadas pelas reformas, com grandes possibilidades de lucros para seus investidores. Nesse sentido e de olho nas oportunidades, a Kroton em abril de 2018, comprou o controle da Somos Educação, num negócio avaliado em mais de 6 bilhões o que faz o grupo aumentar sua participação na educação básica passando de $3 \%$ para $28 \%$. Somos controla os sistemas de ensino Anglo, Ser, Maxi, PH, Ético e Geo, além das editoras Ática, Saraiva e Scipione 5 , um conjunto de escolas de educação básica, assim como, a plataforma educacional PAR. Outras grandes empresas que atuam no ensino superior privado, já trilham uma rota semelhante, tais como, os grupos Estácio e Anima.

\section{CONSIDERAÇÕES FINAIS}

Nesse trabalho procuramos apresentar, de forma breve, os elementos que contribuíram para o fortalecimeto do setor privado mercantil da educação e seu fortalecimento, a partir de meados dos anos 2000 até o final de 2018. Trata-se de um movimento que se fortalece, a partir do falacioso discurso da falta de recursos no cenário pós-golpe de 2016, e que está sendo utilizado para justificar a aceleração de reformas educativas voltadas para $\circ$ mercado e aos interesses dos homens de negócio. No ensino superior, os estímulos são expressivos e envolvem o acesso ao crédito e bolsas, dentro do programa FIES e do PROUNI, empoderaram grandes empresas do setor. Na

\footnotetext{
5 Segundo o FNDE os valores negociados no PNLD com essas três editoras, somaram em 2017 a quantia de $R \$ 455,5$ milhões, equivalente a $35 \%$ " do total.
} 
educação básica, grandes grupos privados de capital aberto se movimentam, focalizando a educação básica para atender os novos requisitos fixados pela BNCC e a Reforma do Ensino Médio. São ações de reforma, na educação básica decorrente da agenda do setor empresarial, ou melhor, dos Reformadores Empresariais, influem mais diretamente nas decisões dentro do MEC e que estão diversificando e ampliando as formas de acesso do setor privado aos fundos públicos.

Se o empoderamento ocorre no período que antecede ao golpe de 2016, é no cenário pós-golpe, com o novo ciclo de reformas educacionais, que se explicitam os interesses e que se abrem novas oportunidades de negócios, para setor privado mercantil atuar em todos os níveis de educação, não apenas na oferta de vagas de uma gama ampla de serviços e produtos.

Por fim, o que estamos assistindo nesses últimos anos é um grande processo que poderá levar a submissão total aos interesses privadomercantis, o que colocará em risco, no futuro próximo, os príncípios democráticos que norteam a oferta da educação como um direito público fundamental. Acompanhar e esse processo é um imperativo para todos aqueles que lutam em defesa da educação pública com gestão pública democrática.

\section{REFERÊNCIAS BIBLIOGRÁFICAS}

BRASIL. Constituição da República Federativa do Brasil. Disponível em: <http://www.planalto.gov.br/ccivil_03/constituicao/constituicao.htm> Acesso em: 20/07/2018.

BRASIL. Emenda Constitucional $\mathbf{N}^{\circ}$ 95. Altera o Ato das Disposições Constitucionais Transitórias, para instituir o Novo Regime Fiscal, e dá outras providências. 2016

BRASIL. Lei $n^{\circ}$ 13.005, de 25 de junho de 2014. Aprova o Plano Nacional de Educação - PNE e dá outras providências. 2014.

BRASIL. Lei $n^{\circ} 11.738$, de 16 de julho de 2008. Regulamenta a alínea "e" do inciso III do caput do art. 60 do Ato das Disposições Constitucionais 
Transitórias, para instituir o piso salarial profissional nacional para os profissionais do magistério público da educação básica. 2008.

BRASIL. Lei $\mathbf{n}^{\circ}$ 11.552, de 19 de novembro de 2007. Altera a Lei $n^{\circ} 10.260$, de 12 de julho de 2001, que dispõe sobre o Fundo de Financiamento ao Estudante do Ensino Superior - Fies. 2007

BRASIL. Lei $\mathbf{n}^{\circ}$ 11.096, de 13 de janeiro de 2005. Institui o Programa Universidade para Todos - PROUNI, regula a atuação de entidades beneficentes de assistência social no ensino superior; altera a Lei $n^{\circ} 10.891$, de 9 de julho de 2004, e dá outras providências. 2005

BRASIL. Lei Complementar 101. Estabelece normas de finanças públicas voltadas para a responsabilidade na gestão fiscal e dá outras providências. 2000.

BURGARELLI, R. Explosão e implosão do FIES: como o ensino superior privado virou o centro dos gastos com educação do governo federal. In: MARINGONI, G. O Negócio da Educação: as aventuras das universidades privadas na terra do capitalismo sem risco. São Paulo: Olho dagua/ FEPESP. 2017, pp 37-54

CARVALHO, L. Valsa brasileira: do boom ao caos econômico. São Paulo: Todavia. 2018.

ESTADÃO. Só 8 grupos concentram $\mathbf{2 7 , 8 \%}$ das matrículas do ensino superior. 08 Junho 2016. Disponível:

https://educacao.estadao.com.br/noticias/geral,apenas-8-grupos-privadosconcentram-27-8-das-matriculas-do-ensino-superior, 10000055857. Acesso em: $13 / 07 / 2017$

FINEDUCA. Nota técnica 1/2016, a aprovação da PEC 241 significa estrangular a educação pública brasileira e tornar letra morta o plano nacional de educação (2014-2024). Disponível em: http://www.fineduca.org.br/wp-content/uploads/2016/10/Nota-conjuntaFINEDUCA-CNDE_01_2016.pdf

FREITAS. L. C. Educadores versus reformadores empresariais: a disputa pela agenda educacional. Revista APASE. n. 13. São Paulo, maio de 2012.

INEP. Censo Escolar. 2016

MACEDO, J. P. et al. Transnacionalização do Ensino Superior: Impactos nos Processos Formativos em Psicologia no Brasil. Psicologia: Ciência e Profissão Out/Dez. 2017 v. $37 n^{\circ} 4,852-868$. 
PIOLLI, E. A valorização docente na Perspectiva do Plano Nacional de Educação (PNE) 2014-2024. Cadernos do CEDES. V.35, n.97, 2015a pp. 483-491

PIOLLI, E. Formação de professores no Brasil no contexto das políticas educacionais atuais. In: Pinheiro, N.V. et al (Orgs). Educação Matemática: diálogos teóricos e metodológicos. São Paulo: Opção. 2015b, pp 50-78.

PMDB; FUNDAÇÃO ULYSSES GUIMARÃES. Uma ponte para o futuro. 2015. Disponivel em: https://www.fundacaoulysses.org.br/wpcontent/uploads/2016/11/UMA-PONTE-PARA-O-FUTURO.pdf. Acesso em: 25/02/2016

RODRIGUES, E. DRU: Mais um ataque à seguridade social. Carta Capital. 2016. https://www.cartacapital.com.br/economia/dru-mais-um-ataque-aseguridade-social. Acesso em: 13/06/2017

SAVIANI, D. O Plano de Desenvolvimento da Educação: análise do projeto do MEC. Educ. Soc., Campinas, vol. 28, n. 100; p. 1231-1255. 2007

SGUISSARDI, V. Modelo de expansão da educação superior no Brasil: predomínio privado/mercantil e desafios para a regulação e a formação universitária. In: Revista Educação e Sociedade, Campinas, vol. 29, n. 105, p. 991-1022, set./dez. 2008.

SINGER, A. A (falta de) base política para o ensaio desenvolvimentista. In: SINGER, A.; LOUREIRO, I. As contradições do Lulismo: a que ponto chegamos? São Paulo: Boitempo. 2016, pp. 21-54.

SOUZA, I. de. A pedagogia do capital: as diretrizes da política pública educacional do estado do Piauí de 2012 a 2018 - gerencialismo, empresariamento e mercadorização da educação pública. 2018. Mimeo

Recebido em: 21 de agosto de 2018 Aprovado em: 12 de outubro de 2018 